\title{
Management of Calvarial Tumors: A Retrospective Analysis and Literature Review
}

\author{
Erkin OZGIRAY ${ }^{1}$, Karthikeyan PERUMAL ${ }^{2}$, Celal CINAR $^{3}$, Kadir Emre CALISKAN ${ }^{1}$, Yesim ERTAN ${ }^{4}$, \\ Taskin YURTSEVEN ${ }^{1}$, Nezih OKTAR ${ }^{1}$, Izzet OVUL ${ }^{1}$, Kazim ONER ${ }^{1}$
}

${ }^{1}$ Ege University, School of Medicine, Department of Neurosurgery, Izmir, Turkey

${ }^{2}$ Illinois Institute of Technology, Department of Health Physics, Chicago, IL, USA

${ }^{3}$ Ege University, School of Medicine, Department of Radiology, Izmir, Turkey

${ }^{4}$ Ege University, School of Medicine, Department of Pathology, Izmir, Turkey

The article is presented as a poster presentation at: "The 14 th European Congress of Neurosurgery (EANS 2012) held in Bratislava, Slovakia, October 24-27, 2012."

\section{ABSTRACT}

AIM: Tumors of various organs that metastasize to bone do not neglect calvarium as a target. The aim of this study was to characterize the calvarial tumors.

MATERIAL and METHODS: We retrospectively reviewed 45 consecutive patients operated for calvarial masses from January 2002 till May 2012 at our hospital. Skull base tumors and patients $\leq 18$ years were excluded.

RESULTS: Three groups of lesions were found - calvarial metastases (15/45), primary tumors (5/45) and tumor-like lesions (25/45). Malignant lesions were equitable by gender distribution, higher age of onset (median age of primary $=55$; secondary $=60$ years) and benign lesions by younger age (median $=35$ ) and female bias $(18 / 25)$. Calvarial metastases mostly presented with local swelling (10/15), local pain (6/15) and rarely neurologic deficit. There was associated dural sinus thrombosis (4/20 of malignant; $1 / 25$ of benign lesions) and osteolysis (3/5 primary malignant, 13/15 secondary and 18/25 of benign lesions). Complete surgical excision was possible with minimal morbidity in all except one patient and nil mortality.

CONCLUSION: Nearly half (20/45) of the calvarial lesions tend to be malignant with most of them presenting as silent painless masses. Surgical excision should be considered only after suitable investigation and appropriate neurosurgical set-up.

KEYWORDS: Skull metastasis, Calvarial tumors, En-bloc resection, Primary tumors, Surgical approach

\section{INTRODUCTION}

$\mathrm{T}$ Tumors of various organs and tissues that tend to metastasize to bony structures do not neglect the skull vault as a target. There are autopsy series of carcinoma breast cases reporting occasional skull metastases even from the end of $18^{\text {th }}$ century. Today and in the near future, we may expect more cases with skull metastasis as a result of advanced radiological imaging and prolonged survival of cancer patients.
Hematogenous metastases to the calvarium can be caused by nearly all types of tumors (8). Most metastatic skull lesions being asymptomatic and less important clinically than intraparenchymal metastatic lesions, they are rarely diagnosed clinically but are frequently found in autopsies. Literature on the skull tumors consists mostly of individual case reports and a scarce number of case series. Only a few articles are available on skull metastases, especially calvarial metastases $(3,4,13,15,16)$. Calvarial metastases signify an advanced stage of disease (16). 
The aim of this article was to present the clinical features and outcome of patients with hematogenous skull tumors located at the the calvarium with a literature review and the analyses of 45 skull lesions, of which 15 were metastases, operated at our institution from January 2002 to May 2012.

\section{MATERIAL and METHODS}

Our institution is a tertiary hospital catering to a population of about ten million from Izmir and neighbouring small cities. In this retrospective study, we included 45 consecutive adult patients who underwent surgery for a skull lesion at our department between January 2002 and May 2012, identified from the Department of Neurosurgery database.

Clinical information obtained by a retrospective chart review included age, gender, symptoms, type of primary tumor, treatment of the primary and secondaries, presenting systemic metastases, neurological status before and after surgery, treatment complications and neurological outcome (long-term and short-term). All living patients were contacted by telephone to determine their current neurological status.

All radiological images [plain skull films, computed tomography scans (CT), magnetic resonance imaging (MRI), angiograms] were reviewed to analyze the site of tumor location in the calvarium, involvement of the cranium, scalp, dura, or brain, associated intracranial metastases or meningeal dissemination, and dural venous sinus patency. Operative reports were reviewed to determine whether en bloc or piecemeal resection was performed. The extent of resection was determined by reviews of postoperative CT or MRI scans.

Patient consent for using clinical data was obtained in every case by having the patient sign the hospital form. Patients with cranial base metastases/tumors, who were younger than 18 years, and who could not consent for using their data for the study were excluded from the analysis.

The diagnosis was confirmed by histopathological examination. The patients were followed at our outpatient department.

Descriptive statistics were performed to summarize the patients' characteristics. For statistical analysis, SPSS version 17.0 was used.

We performed an extensive literature review in the Pubmed database, focusing publications in English Language from the years 1950 to 2013, using a total of 16 key search items (Calvarial tumors; Calvarial secondaries; Calvarial metastasis; Calvarial neoplasms; Treatment of Calvarial tumors; metastases to skull; skull secondaries; Tumors of the Skull; Neurosurgery Calvarium; Calvarial Surgery; Neoplasms of skull; Treatment of skull tumors, Vault tumors, Vault mass, Calvarial mass, skull mass), yielding a total of 2533 results.

We filtered out all non-human and all non-clinical search results. We also excluded all search results that were not pertinent to the three primary questions of interest, i.e., clinical features, radiological features and management of calvarial tumors, and were left with 33 relevant articles. We have summarized some of the important articles in this manuscript.
Publications about the clinical presentation of skull metastases are rare. To the best of our knowledge, this is one of the few articles discussing the clinical features, differential diagnosis and treatment of calvarial metastasis.

\section{RESULTS}

Our study population had a median age of 44 years (range: 18 to 82). The male:female ratio was 1:1.8. According to histopathology, skull metastases was diagnosed in 15 , primary skull tumors in 5 and benign/tumor-like lesions in 25 cases (Table I).

Nearly one-third of our patients (15/45) had calvarial metastases. Most patients presented initially with local swelling (10/15), sometimes accompanied by local pain (6/15). A neurological deficit (right hemiparesis) was present in only 1 case that was located at the left parietal region.

Nine of the 15 patients diagnosed with metastasis were suffering from a previously diagnosed primary. The average duration between the primary malignancy and the surgery for the calvarial metastasis was 29.1 months. All other six cases

Table I: Nature of Disease: Histologically Confirmed Diagnosis of Skull Lesions

\begin{tabular}{|c|c|c|}
\hline Group & Histology & Frequency \\
\hline \multirow{3}{*}{$\begin{array}{l}\text { Primary skull } \\
\text { tumors }\end{array}$} & Myeloma & 3 \\
\hline & Sclerosing Osteoblastoma & 1 \\
\hline & Malignant Meningioma & $\begin{array}{c}1 \\
n=5\end{array}$ \\
\hline \multirow{10}{*}{$\begin{array}{l}\text { Skull } \\
\text { metastases }\end{array}$} & $\begin{array}{l}\text { Adenocarcinoma Unknown } \\
\text { Primary }\end{array}$ & 5 \\
\hline & Thyroid Cancer & 3 \\
\hline & Chondrosarcoma & 2 \\
\hline & Breast carcinoma & 1 \\
\hline & Cholangiocarcinoma & 1 \\
\hline & Squamous Cell carcinoma & 1 \\
\hline & Unknown Primary & \\
\hline & Unknown Pathology & 1 \\
\hline & Colon Cancer & 1 \\
\hline & & $n=15$ \\
\hline \multirow{7}{*}{ Benign } & Epidermoid Cyst & 8 \\
\hline & Simple Bone Cyst & 2 \\
\hline & Meningioma & 3 \\
\hline & Plasmacytoma & 1 \\
\hline & Langerhans cell histiocytosis & 4 \\
\hline & Benign Giant Cell tumor & 1 \\
\hline & & $n=19$ \\
\hline \multirow{4}{*}{$\begin{array}{l}\text { Tumor-like } \\
\text { lesions }\end{array}$} & Fibrous dysplasia & 4 \\
\hline & Calcified Chronic subdural & 1 \\
\hline & hematoma & 1 \\
\hline & & $\mathrm{n}=6$ \\
\hline
\end{tabular}


were calvarial metastases with occult primary at the time of the surgery. All the patients diagnosed as metastasis were referred to the primary physician or oncologist for further management.

In our series, reconstruction of the skull defect due to a lesion was always performed in a second session depending on the patient's preference even when the case was benign. There was need for time to determine whether the lesion was benign or malignant. Patients with benign lesions and large defects were operated for the second time about 2-3 months after the first surgery. Most of the patients with small defects did not prefer reconstruction in our series.

Our series was characterized by zero mortality and without excessive intra-operative bleeding and post-operative complications.

\section{Illustrative Cases}

Case 1: A 33-year-old lady presented to our department with a cranial MRI depicting an intra-calvarial tumor at the right side of the frontal bone (Figure 1A-D). She had been suffering from headache for two years with no local swelling, tenderness or neurological deficit. The mass lesion was incidentally detected and en-bloc resection was planned according to the patient's decision. The mass was resected en-bloc under local anesthesia with mild sedation. One burr-hole craniectomy following a linear skin incision was performed. There was no dural attachment and the dura was kept intact at the end of the resection. She was discharged the following day after an uneventful recovery. Histopathology showed Langerhans cells with round nuclei and prominent nuclear groove, eosinophils and lymphocytes. Immunohistochemistry showed cells positive for CD1a and S100. Final pathological diagnosis was Langerhans cell histiocytosis.

Case 2: A 51-year-old lady was referred to our department after an eventful attempt to resect her calvarial mass at a peripheral institution. She was asymptomatic a few months ago when she noticed a painless mass on her right occiput. She was informed of a simple procedure to remove the painless mass beneath the skin under local anesthesia and

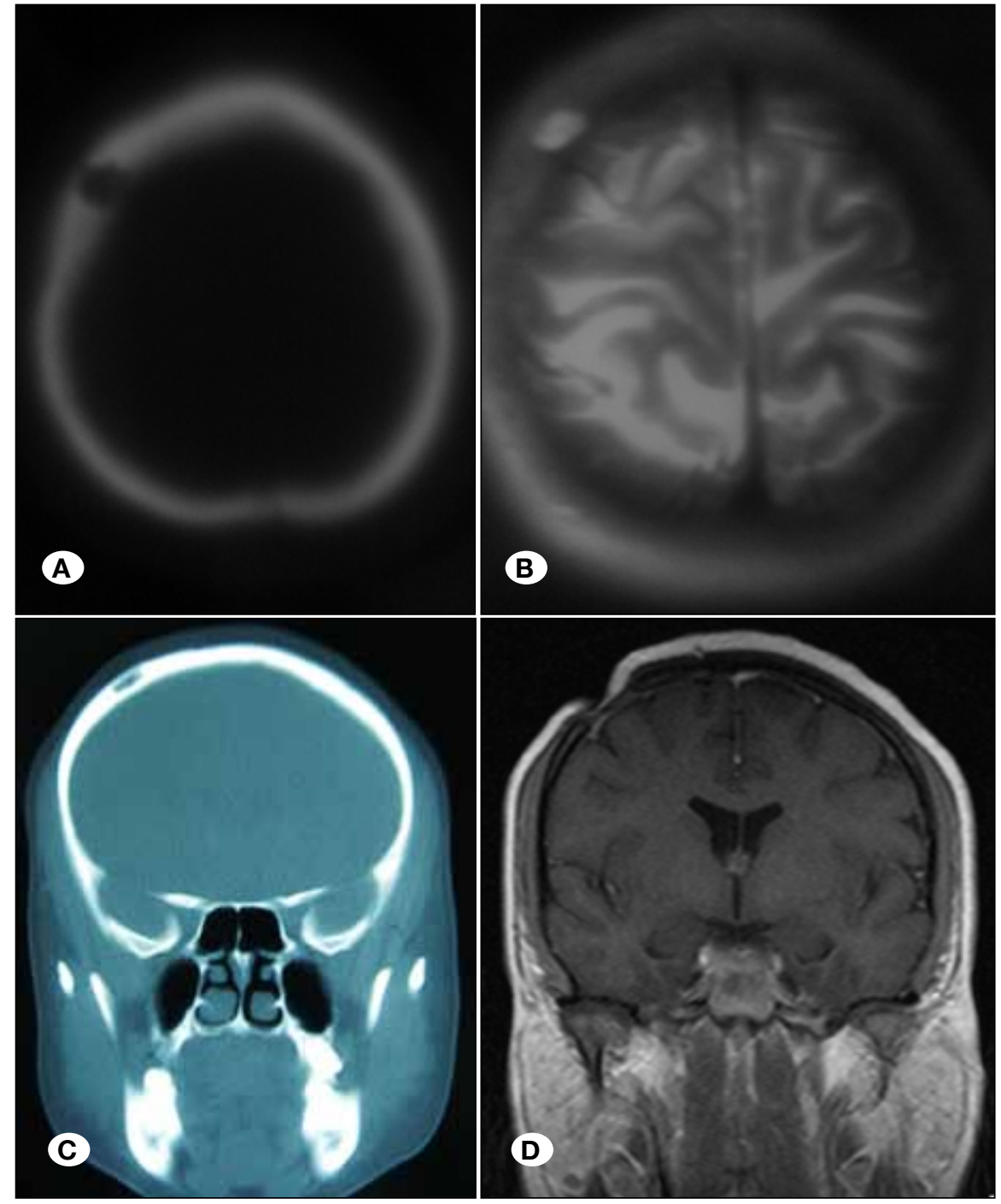

Figure 1: Pre-operative axial CT-scan (A), axial T2-weighted MRI images (B) depicting the intra-calvarial mass located at the right side of the frontal bone. C) Pre-operative coronal CT images depicting the intracalvarial mass located at the right side of the frontal bone, D) Post-operative coronal T1-weighted MRI images confirming the removal of the intra-calvarial mass lesion. 
unexpected profuse bleeding resulted in sudden decrease of the arterial tension and urgent closure of the wound even before taking a biopsy for histological examination. She was then immediately referred to our department for further surgical evaluation and management. Radiological work-up depicted a calvarial mass located at right side of the occipital bone on the top of the right transverse sinus (Figure 2A-D). The right transverse sinus was patent, but the inferior wall of the sinus seemed to be partially invaded by the tumor. En-block resection under general anesthesia was planned. A central catheter was placed and other routine preventive measures were taken before turning the patient to the prone position with the head retained in a Mayfield three-pin fixator. Two units of cross-matched packed red blood cells were kept ready in the operation room. After the skin incision, en-bloc resection was performed via a single burr-hole. Profuse bleeding from a minimal laceration on the invaded wall of the transverse sinus was controlled via absorbable collagen matrix and the sinus was kept patent at the end. No air emboli were detected and the patient was discharged after an uneventful recovery on the second post-operative day. On histological examination, follicular-patterned tumor cells, which were small, round and monotonous similar to normal thyroid follicular cells were observed. There was colloid in some of the follicles. Immunohistochemistry showed positivity for thyroid transcription factor-1 and thyroglobulin. Final pathological diagnosis was metastatic follicular carcinoma of the thyroid and further oncological management was planned. She is still alive without any neurological deficit on the sixth year of her follow-up.

Case 3: A 67-year-old male patient presented to our department with a giant mass on the top of his calvarium. He was complaining of the progressive growth in the last two years and abrasion on its top for last several months. There was no neurological deficit. The mass was first noticed more than 40 years ago after a cranial trauma during a motor vehicle accident. The mass was growing insidiously for decades and he had not sought medical attention despite suggestions by his family. The growth had accelerated in the last two years and the skin on top was ulcerated with occasional bleeding in the last several months, forcing the patient to seek medical attention for the first time. The mass was immobile and fixed to the calvarium. The skin on the top was ulcerated, probably due
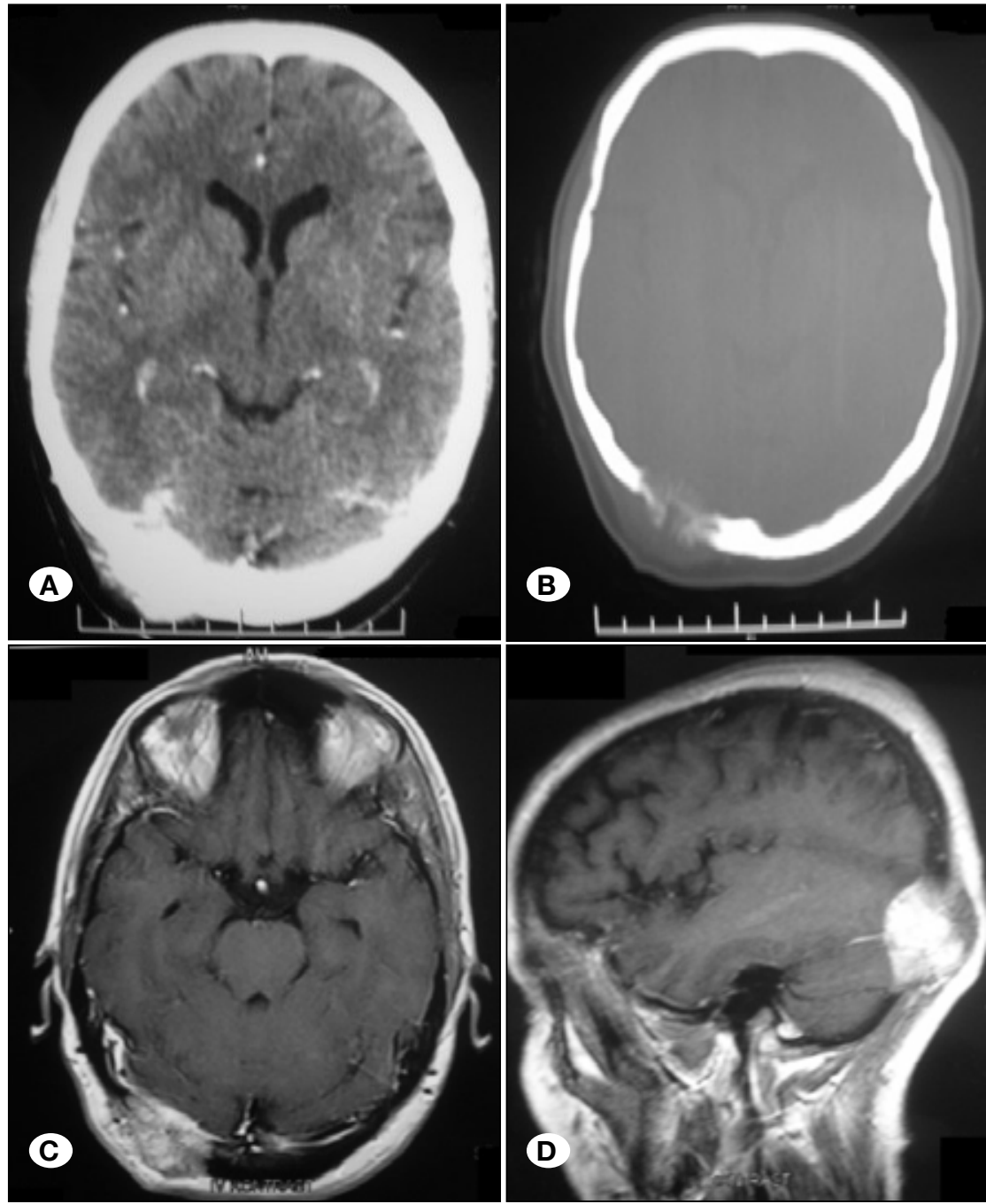

Figure 2: A) Pre-operative axial CT-scan images depicting contrast-enhancement in the cerebral window, B) destruction due to the lesion in the bone window. C, D) Pre-operative axial and sagittal MR images depicting the contrast enhancement of the tumor overlying the transverse sinus. 
to physical friction. X-rays and CT-scans suggested a mass calcified at the bottom. Pre-operative contrast-enhanced MRI depicted contrast enhancement within the tumor and the dura and suggested a calcified meningioma (Figure $3 A-C)$. DSA was performed to evaluate the feeders. Interventional radiologists confirmed large feeders originating from superficial temporal arteries and performed embolization (Figure 3A-C). Considering the patient's choice, a partial resection was planned. The patient asked for cosmetic refinement and did not accept the risks of radical resection resulting from a superior sagittal sinus intervention. The patient was placed in the semi-sitting position under general anesthesia. After the skin incision, the flap covering the tumor was easily peeled away. There was minimal bleeding, much less than expected, due to pre-operative embolization. The base was razored via high-speed drill and the remaining skin was also removed. A drainage tube was left under the skin and it was closed in customary fashion. After an uncomplicated and uneventful recovery, he was
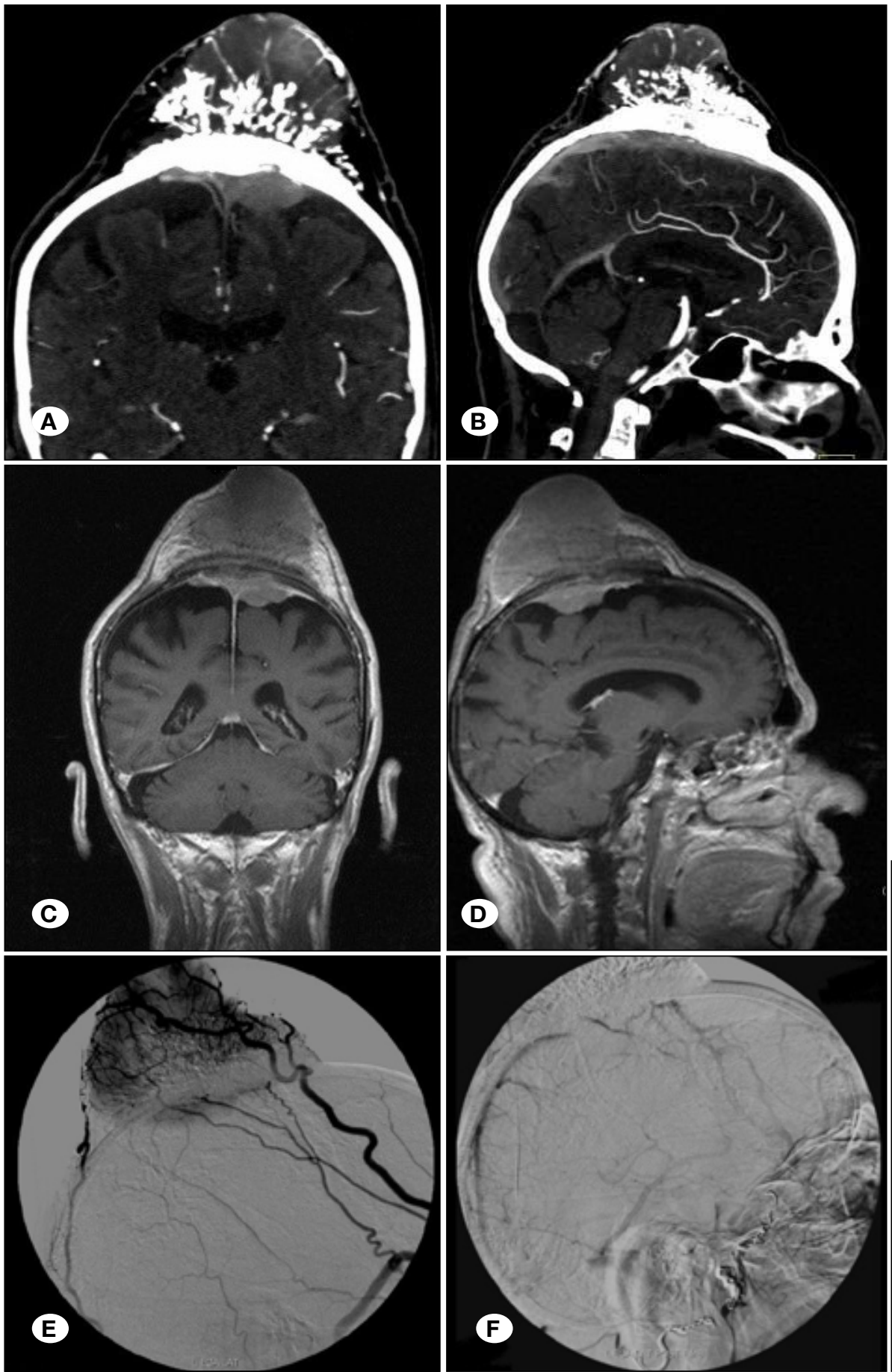

Figure 3:

A,B) Pre-operative cranial coronal and sagittal CT scans with contrast show huge arterialization of the mass lesion.

C,D) Pre-operative coronal and sagittal T1-weighted MRI scans show the mass lesion.

E) Pre- embolisation DSA that shows high vascularization of the mass.

F) Post-embolisation images of DSA. G) 3D CT reconstruction of the giant calcified calvarial mass depicting its feeders and rich vascularization prior to the surgery. 
discharged on the fifth post-operative day. This case is the only partial resection in our series due to the patient's limited consent. He was seeking medical care for cosmetic refinement and did not want to take the risk of a complete resection.

\section{- DISCUSSION}

The calvarium is a frequent target site of involvement for common neoplasms (8). Most metastatic skull lesions are asymptomatic, although they can cause severe disability due to compression of dural sinuses, eloquent cortex and cranial nerves (16). Despite the fact that hematogenous skull metastases can be caused by nearly all types of tumors, skull metastases are rarely diagnosed clinically, but are frequently found in autopsies (16).

Modern imaging techniques have increased the diagnosis of calvarial metastases. Articles on calvarial neoplasms can be found in journals of many different specialties, but only a few of them describe the clinical features, differential diagnosis and management of calvarial metastases as a separate entity (16).

Calvarial masses can be classified into three groups: 1) Benign lesions 2) Tumor-like lesions 3) Malignant lesions. Solitary calvarial neoplasms not involving the dural sinus require simple en-bloc resection. Frequently, the underlying dura may be attached to the benign mass due to the long-term pressure, requiring tedious stripping to preserve the dura, primary suturing or autologous grafting. Some of the pertinent literatures is summarized in Table III.

The neurosurgical literature lacks large series highlighting calvarial tumors. Constans and Donzelli (6), in a 1981 series of 14 patients with calvarial metastases treated for more than 20 years between 1957 and 1979 , stated that $50 \%$ of the lesions caused irritation of the central nervous system and cranial metastasis was the first evidence of the primary tumor in six of the 14 cases (6). In 2003, Stark et al., reported that only 1 of 12 cases presented with neurological deficit and the calvarial metastasis was prior to the primary tumor again only in one patient (16). This may be due to the advances in radiology and probable lead time variation in diagnosis.

The presentation of skull metastases varies depending on the pathology. Although they are silent, painless and diagnosed incidentally by the physician most of the time, they may cause pain, skin ulcerations, and more importantly neurological symptoms due the compression of the underlying brain cortex. Skull metastases may reach considerable size and lead to compression of dural sinuses and cranial nerves $(1,2,7)$.

Stark et al. concluded that skull metastases have clinical features distinctive from those of primary skull tumors and tumor-like lesions (16). Skull metastases can cause local painless swelling (16) rarely leading to neurologic dysfunction. The duration of symptoms is usually short. The clinical features of skull metastases were compared to those of primary skull tumors and benign tumor-like lesions. In our study the patients were mainly asymptomatic. However, some patients suffered from local pain or neurological deficit that harmed their quality of life. In the study by Stark et al. (16) patients with skull metastases were characterized by higher age and shorter duration of symptoms. In comparison to patients with primary skull tumors, patients with skull metastases presented less frequently with neurologic deficit and less frequently with skull base lesions. In our study we found that skull metastases were characterized by higher age and shorter duration of symptoms similar to Stark et al. (16). Contrary to Stark et al. (16), patients with skull metastases in our study presented more frequently with neurologic deficit than primary skull tumor patients and less frequently than tumor-like lesions (Table II).

Skeletal metastases of neuroblastomas are characteristically multiple, and calvarial deposits usually show simultaneous involvement of the orbit (9). Ewing's sarcoma (ES) usually presents as a solitary bony lesion (10).

Metastatic skull tumors are mostly calvarial circumscribed intraosseous tumors (14). Radionuclide bone studies are a valuable screening test to detect bone metastases. With $\mathrm{CT}$ and MRI, bone metastases extending intracranially and primary dural metastases show the characteristic biconvex shape, usually associated with brain displacement away from the inner table. CT is better in detecting skull base erosion and MRI provides more detailed information about dural involvement, perineural and perivascular spread (12).

Mitsuya et al., on reviewing images of patients undergoing routine head MRI, found that 175 out of 1265 patients had metastatic skull tumors. Primary sites were breast cancer (55\%), lung cancer (14\%), prostate cancer (6\%), malignant lymphoma (5\%), and others (20\%). Calvarial metastases were most frequently circumscribed and intraosseous (27\%)(14).

Osteolytic calvarial lesions are infrequent findings (11). In a retrospective chart review study by Hong et al., the most common histopathological diagnoses were metastasis $(n=9)$, Langerhans-cell histiocytosis $(n=9)$ and intraosseous hemangioma $(n=5)$. Osteolytic calvarial lesions could be found in any age group (11).

Michael et al., in their retrospective chart review on calvarial metastases overlying dural sinuses in 13 patients (with a median age of 54 years), found that 11 involved the superior sagittal sinus, and 2 involved the transverse sinus. Renal cell carcinoma and sarcoma were the most common primary tumors. In nine patients, the involved sinus was resected, and in four patients, the sinus was reconstituted after tumor removal (13).

MRI contributes to understanding the type, location, multiplicity and the relationship with the brain, cranial nerves and dural sinuses (13). Dural sinus thrombosis, a dreaded co-morbidity of calvarial metastases, can be difficult to diagnose. Angiography is considered the "gold standard"; MRI offers a method of demonstrating the dural sinuses in multiple planes and flow within the sinuses may be depicted by MR angiography (MRA). Chaudhuri et al. reported on three cases where the diagnosis of superior sagittal sinus thrombosis due to calvarial metastases was missed by $\mathrm{CT}$, primarily due to their site over the convexity, but was demonstrated accurately using MRI with MRA (5). Enhanced MR images were superior to nonenhanced studies for detecting subtle intradiploic metastases (18). 
Table II: Comparison of Clinical Features in 45 Patients

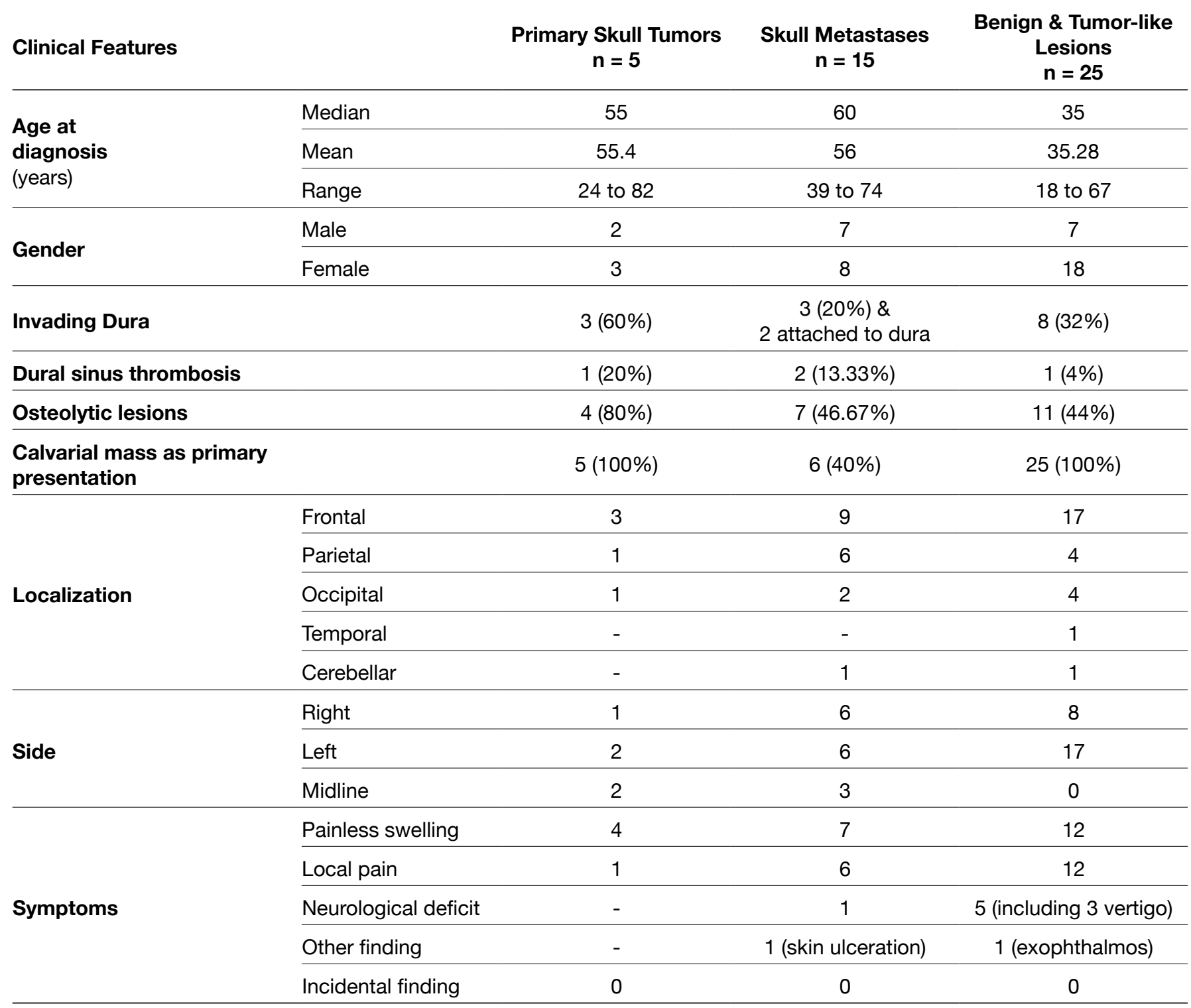

There are no standardized algorithms and management of skull metastases depends on histopathology, extent of spread and associated co-morbidities (11). Wecht and Sawaya, in 1997 , with 42 cases of calvarial involvement from benign and malignant disease, which constitutes one of the largest series, concluded that surgery should be done: a) to establish the diagnosis, b) for solitary malignant lesions, and c) for total excision of benign and symptomatic lesions (17). Due to low surgical morbidity, Hong et al. recommended complete resection of osteolytic calvarial lesions with reconstruction when feasible (11).

Complete extirpation of calvarial metastases overlying dural sinuses was associated with slightly more morbidity, but the overall recurrence and survival rates of patients with dural sinus calvarial metastases were similar. En bloc resection was as safe as piecemeal resection and is more effective in limiting operative blood loss (13). Radiation therapy improved the quality of life of patients with neurological symptoms (13).

In agreement with Constans and Donzelli (6), Stark et al. suggested that surgery is a safe palliative procedure with low morbidity and low mortality (16). In our series we did not have any mortality or even neurological morbidity due to surgical removal. Although we state that resection of calvarial masses is safe, the decision for surgery should be made under the stated circumstances with a multidisciplinary approach.

\section{CONCLUSION}

Calvarial tumors, whether benign or malignant, are amenable to surgical resection. Meticulous radiological evaluation and surgical planning prior to the surgery is mandatory to ensure low morbidity and mortality. 
Table III: Selected Literature on Calvarial Tumors

\begin{tabular}{|c|c|c|c|c|c|}
\hline No. & Author & Study method & $\begin{array}{c}\text { No. of } \\
\text { Patients }\end{array}$ & Diagnostic/Therapeutic & Findings \\
\hline 1 & $\begin{array}{l}\text { Bernstein } \\
\text { et al. (1974) }\end{array}$ & Retrospective & 34 & $\begin{array}{l}\text { Diagnostic - }{ }^{99 m} T c \text { Radionuclide } \\
\text { scan in malignant patients. }\end{array}$ & $\begin{array}{l}\text { Rim enhancement decreased in delayed } \\
\text { views in calvarial lesion; In intracerebral } \\
\text { lesions - rim enhancement increases. }\end{array}$ \\
\hline 2 & $\begin{array}{l}\text { Becker } \\
\text { et al. (1978) }\end{array}$ & Retrospective & 50 & $\begin{array}{l}\text { Diagnostic - CT scan vs. } \\
\text { Radionuclide }(\mathrm{RN}) \text { scan in } \\
\text { malignant patients. }\end{array}$ & $\begin{array}{l}\text { RN Scan is important for early } \\
\text { demonstration of skull metastases. } \\
\text { CT Scan is } 75-80 \% \text { as sensitive as RN } \\
\text { scan. }\end{array}$ \\
\hline 3 & $\begin{array}{l}\text { Michele SW } \\
\text { et al. (1990) }\end{array}$ & Retrospective & 14 & $\begin{array}{l}\text { Diagnostic - MRI scan in } \\
\text { malignant patients }\end{array}$ & $\begin{array}{l}\text { Both Enhanced and Non-enhanced MRI } \\
\text { studies are required to obtain accurate } \\
\text { evaluation of Calvarial disease. }\end{array}$ \\
\hline 5 & $\begin{array}{l}\text { Stark et al. } \\
(2003)\end{array}$ & Retrospective & 38 & $\begin{array}{l}\text { Descriptive study on skull } \\
\text { tumor patients (primary, } \\
\text { secondary and benign/ } \\
\text { tumor-like lesions). }\end{array}$ & $\begin{array}{l}\text { Skull metastases have characteristic } \\
\text { clinical features that are distinctive from } \\
\text { those of primary skull tumors and tumor- } \\
\text { like lesions. } \\
\text { Surgery is a safe palliative procedure } \\
\text { with low morbidity and low mortality. }\end{array}$ \\
\hline 6 & $\begin{array}{l}\text { Moon et al. } \\
(2007)\end{array}$ & Prospective & 13 & $\begin{array}{l}\text { Diagnostic - diffusion-weighted } \\
\text { imaging (DWI) with sensitivity } \\
\text { encoding (SENSE) } \\
\text { T1-weighted imaging (T1WI) on } \\
\text { patients with suspected cranial } \\
\text { secondaries. }\end{array}$ & $\begin{array}{l}\text { In conjunction with conventional MR } \\
\text { sequences DWI with SENSE aid in the } \\
\text { detection of cranial bone metastases. }\end{array}$ \\
\hline 8 & $\begin{array}{l}\text { Ozgiray et al. } \\
\text { (Current study) }\end{array}$ & Retrospective & 45 & $\begin{array}{l}\text { Descriptive study on skull } \\
\text { tumor patients (primary, } \\
\text { secondary and benign/tumor } \\
\text { like lesions). }\end{array}$ & $\begin{array}{l}\text { Surgical resection of calvarial tumor } \\
\text { (if indicated) should be undertaken in } \\
\text { the tertiary hospital only after proper } \\
\text { evaluation and set-up. }\end{array}$ \\
\hline
\end{tabular}

\section{ACKNOWLEDGEMENT}

The procedures followed were in accordance with the ethical standards of the responsible committee on human experimentation (institutional or regional) and with the Helsinki Declaration of 1975 that was revised in 2000.

\section{REFERENCES}

1. Artico M, De Caro GM, Salvati M, Carloia S, Rastelli E, Wierzbicki V, Manni M: Solitary metastases to the cranial vault. Report of ten cases. J Neurosurg Sci 44(1):33-38, 2000
2. Aydin VM, Cekinmez M, Kizilkilic O, Kayaselcuk F, Sen O, Altinors $\mathrm{N}$ : Unusual case of skull metastasis secondary to pancreatic adenocarcinoma. Pathol Oncol Res POR 11(3):182-183, 2005

3. Becker H, Norman D, Boyd DP, Hattner RS, Newton TH: Computed tomography in detecting calvarial metastases: $A$ comparison with skull radiography and radionuclide scanning. Neuroradiology 16:504-505, 1978

4. Bernstein J, Hoffer PB: Use of the delayed brain scan in differentiating calvarial from cerebral lesions. J Nucl Med 115(8):681-684, 974 
5. Chaudhuri R, Tarnawski M, Graves MJ, Graves PE, Cox TC: Dural sinus occlusion due to calvarial metastases: A CT blind spot. J Comput Assist Tomogr 16(1):30-34, 1992

6. Constans JP, Donzelli R: Surgical features of cranial metastases. Surg Neurol 15(1):35-38, 1981

7. Ferrandina G, Testa AC, Zannoni GF, Poerio A, Scambia G: Skull metastasis in primary vulvar adenocarcinoma of the Bartholin's gland: A case report. Gynecol Oncol 98(2):322324, 2005

8. Gaetani P, Di leva A, Colombo P, Tancioni F, Aimar E, Debernardi A, Baena RR: Calvarial metastases as clinical presentation of renal cell carcinoma: Report of two cases and review of the literature. Clin Neurol Neurosurg 107(4):329-333, 2005

9. Grover SB, Pati NK, Saluja S, Bhowmik KT: Solitary calvarial metastases: An unusual presentation of thoracic neuroblastoma. Indian J Cancer 40(3):120-122, 2003

10. Güzel A, Tatli M, Er U, Yilmaz F, Bavbek M: Multifocal Ewing's sarcoma of the brain, calvarium, leptomeninges, spine and other bones in a child. J Clin Neurosci 15(7):813-817, 2008

11. Hong B, Hermann EJ, Klein R, Krauss JK, Nakamura M: Surgical resection of osteolytic calvarial lesions: Clinicopathological features. Clin Neurol Neurosurg 112(10):865-869, 2010
12. Maroldi R, Ambrosi C, Farina D: Metastatic disease of the brain: Extra-axial metastases (skull, dura, leptomeningeal) and tumour spread. Eur Radiol15(3):617-626, 2005

13. Michael CB, Gokaslan ZL, DeMonte F, McCutcheon IE, Sawaya R, Lang FF: Surgical resection of calvarial metastases overlying dural sinuses. Neurosurgery 48(4):745-754, 2001

14. Mitsuya K, Nakasu Y, Horiguchi S, Harada H, Nishimura T, Yuen S, Asakura K, Endo M: Metastatic skull tumors: MRI features and a new conventional classification. J Neurooncol 104(1):239-245, 2011

15. Moon WJ, Lee MH, Chung EC: Diffusion-weighted imaging with sensitivity encoding (SENSE) for detecting cranial bone marrow metastases: Comparison with T1-weighted images. Korean J Radiol 8(3):185-191, 2007

16. Stark AM, Eichmann T, Mehdorn HM: Skull metastases: Clinical features, differential diagnosis, and review of the literature. Surg Neurol 60(3):219-225, 2003

17. Wecht DA, Sawaya R: Lesions of the calvaria: Surgical experience with 42 patients. Ann Surg Oncol 4(1):28-36, 1997

18. West MS, Russell EJ, Breit R, Sze G, Kim KS: Calvarial and skull base metastases: Comparison of nonenhanced and GdDTPA-enhanced MR images. Radiology 174(1):85-91, 1990 